\title{
Aging and Clearance of Erythrocytes
}

\author{
Christoph Gassner \\ Molecular Diagnostics and Cytometry, Blutspende Zürich, Schlieren, Switzerland
}

As an intro, Beatrix Grubeck-Loebenstein [1] in her function as honorary editor to 'Experimental Gerontology' and Director of the Institute for Biomedical Aging Research, in Innsbruck, Austria, describes the topic of aging research in general. She teaches the correct wording and details the various research approaches in this field.

Storage lesions, buffering and nutrient conditions, and possibly nitric oxide homeostasis may be the first associations coming to a transfusionists' mind, when confronted with the key words 'erythrocyte aging' and 'erythrocyte clearance'. However, the term 'aging' was meant to describe the natural processes first, rather than topics of in vitro aging in blood bags. This special issue of Transfusion Medicine and HemoTHERAPY on Aging and Clearance of Erythrocytes is intended to mainly focus on the natural processes of erythrocyte aging, rather than aspects of erythrocyte storage. In order to get a correct and clear understanding of the natural curriculum vitae of an erythrocyte, it seems mandatory to strictly discriminate between in vivo and in vitro processes. Therefore, the authors of this issue were strongly encouraged to discuss and rank their individual research findings with respect to their significance for the natural process of erythrocyte aging and clearance.

To investigate such processes, 'cellular age' needs to be measured, and Robert S. Franco [2] is reviewing useful and accessible parameters to address this issue. Per Arne Oldenborg [3] is reviewing receptor/ligand interactions of SIRP $\alpha$ and CD47 and its role in sensing old erythrocytes. For once, transfusion specialists may find a transfusion-independent, alternative impact of auto-antibodies, as directed against band 3 and with biological relevance for erythrocyte clearance as reviewed by Hans U. Lutz [4]. CD47 is addressed in two additional contributions in this issue. One review by Patrick Burger and coauthors [5] deals with the two different conformational states of this molecule, which are put into context of age signaling. In the second article by Rajiv K. Saxena and coauthors [6] the role of this target molecule for an in vivo biotinylation technique in order to assess erythrocyte ageing in mice is described.

In the past, understanding of natural biological mechanism widely profited from observations made in pathological situations. However, these basic principles of pathological conditions may not be ruled out as additional contributors in healthy erythrocyte aging and clearance a priori. It is therefore that Paulo Arese and coauthors [7] describe life and fate of glucose 6 phosphate dehydrogenase-deficient erythrocytes, and Marleen Straat and coauthors [8] the process of red blood cell clearance in inflammation. In this context, erythrocytes may experience survival-threatening injury prior to senescence and enter programmed cell death, known as eryptosis, a process similar, but still distinct from apoptosis which is reviewed by Florian Lang and coauthors [9].

Last but not least, microparticles, which are found in both natural blood and stored erythrocytes, may not simply be considered as degradative cell fragments or 'dust' without any biological function, but are now recognized as being involved in a broad spectrum of biological activities including thrombosis, hemostasis, and inflammation. Their role with special focus on natural erythrocyte aging will be highlighted by the working group of Jean-Daniel Tissot [10].

After reading the above mentioned articles, you may consider yourself as an expert in erythrocyte aging and clearance and well be able to answer the following questions: 'Did you know, that the age of erythrocytes in different individuals may vary in between 99 and 145 days? Do erythrocytes of old people die earlier, as compared to those found in younger individuals? Could you imagine an age factor matching for individual donor erythrocytes to be transfused in order to improve their lifespan in different recipients?' If you find yourself unable to answer these questions, you may not have been missing something, but you might got hooked by the topic of erythrocyte aging and clearance, and wish to dive deeper into this fascinating biological topic.

\section{KARGER \\ Fax +497614520714 \\ Information@Karger.de}

www.karger.com
(C) 2012 S. Karger GmbH, Freiburg

$1660-3796 / 12 / 0395-0297 \$ 38.00 / 0$

Accessible online at:

www.karger.com/tmh
PD Dr. Christoph Gassner

Molecular Diagnostics and Cytometry

Blutspende Zürich

Rütistrasse 19, 8952 Schlieren, Switzerland

c.gassner@zhbsd.ch 


\section{References}

1 Grubeck-Loebenstein B: What is ageing? Transfus Med Hemother 2012;39(5):299-300

2 Franco RS: Measurement of red cell lifespan an aging. Transfus Med Hemother 2012;39(5):302307.

3 Oldenborg P-A: Role of CD47 and signal regulatory protein alpha $(\mathrm{SIRP} \alpha)$ in regulating clearance of viable or aged blood cells. Transfus Med Hemother 2012;39(5):315-320.

4 Lutz HU: Naturally occurring anti-band 3 antibodies in clearance of senescent and oxidatively stressed human red blood cells. Transfus Med Hemother 2012;39(5):321-327.
5 Burger P, de Korte D, van den Berg TK, van Bruggen R: CD47 in erythrocyte ageing and clearance the Dutch point of view. Transfus Med Hemother 2012;39(5):348-352.

6 Saxena RK, Bhardwaj N, Sachar S, Puri N, Khandelwal S: A double in vivo biotinylation technique for objective assessment of aging and clearance of mouse erythrocytes in blood circulation. Transfus Med Hemother 2012;39(5):335-341.

7 Arese P, Gallo V, Pantaleo A, Turrini F: Life and death of glucose-6-phosphate dehydrogenase (G6PD) Deficient erythrocytes - role of redox stress and band 3 modifications. Transfus Med Hemother 2012;39(5):328-334.
Straat M, van Bruggen R, de Korte D, Jufferman NP: Red blood cell clearance in inflammation. Transfus Med Hemother 2012;39(5):353-360.

9 Lang F, Lang E, Föller M: Physiology and pathophysiology of eryptosis. Transfus Med Hemother 2012;39(5):308-314

10 Rubin O, Canellini G, Delobel J, Lion N, Tissot JD: Red blood cell microparticles: clinical relevance. Transfus Med Hemother 2012;39(5):342347. 